\title{
Formação continuada de professores alfabetizadores no âmbito do PNAIC: contribuições para as práticas de ensino da leitura e da escrita
}

Silva, Alexsandro da Souza, Aline Gomes $\mathrm{de}^{2}$

\section{Resumo}

A formação continuada de professores tem sido reconhecida, cada vez mais, como um direito e uma necessidade. Nesse cenário, especialmente a partir do início do século XXI, diversos programas governamentais de formação continuada de professores têm sido ofertados às redes públicas de ensino do país. O presente artigo apresenta resultados de uma pesquisa que teve como objetivo analisar as contribuições do curso de formação continuada do Pacto Nacional pela Alfabetização na Idade Certa, realizado no ano de 2013, para as práticas de ensino da leitura e da escrita de 10 (dez) professoras alfabetizadoras participantes do curso no referido ano na cidade de Brejo da Madre de Deus - PE. Para tanto, como procedimento metodológico, utilizamos a entrevista semiestruturada, a qual gerou dados que foram submetidos à analise temática de conteúdo. Os resultados revelam-nos que parece ter havido a incorporação de algumas propostas da formação no ensino da leitura e da escrita, sobretudo no que se refere ao trabalho com os gêneros textuais e à ludicidade. Entretanto, essa incorporação não acontece como uma mera reprodução, mas, sim, a partir das experiências vivenciadas cotidianamente pelos professores.

Alfabetização. Leitura e Escrita. PNAIC.

\section{Abstracto}

La formación continua de los profesores ha sido reconocida cada vez más como un derecho y una necesidad. En este escenario, sobre todo desde el principio del siglo XXI, varios programas gubernamentales de formación continua de los maestros han sido ofrecidos a las redes públicas de enseñanza del país. Este artículo presenta resultados de una investigación que tuvo como objetivo analizar las contribuciones del curso de formación continuada del "Pacto Nacional pela Educação na Idade Certa", desarollado en 2013, para las prácticas de enseñanza, de lectura y escritura de 10 (diez) profesoras alfabetizadores participantes del curso en el referido año en la ciudad de Brejo da Madre de Deus - PE. De esa manera, como procedimiento metodológico, utilizamos la entrevista semiestructurada, que generó los datos que fueron sometidos a análisis temática de contenido. Los resultados nos muestran que parece haber tenido la incorporación de algunas propuestas de la formación en la enseñanza de la lectura y de la escritura, sobre todo cuando se trata del trabajo con los géneros textuales y el lúdico. Sin embargo, esta

1 Doutor em Educação. Professor associado do Núcleo de Formação Docente, atuando no curso de Licenciatura em Pedagogia. Professor do Programa de Pós-Graduação em Educação Contemporânea e no Programa de Pós-Graduação em Educação, ambos da UFPE. Membro do Centro de Estudos em Educação e Linguagem (CEEL) da UFPE.

2 Graduanda em Pedagogia. Bolsista de Iniciação Científica (CNPq/PROPESq - UFPE). 
incorporación no se produce como una mera reproducción, sino desde las experiencias vividas a diario por los profesores.

Alfabetización. Lectura y Escritura. PNAIC.

\section{Introdução}

A formação continuada de professores é reconhecida, hoje, como uma necessidade e um direito. Necessidade, porque a formação docente não acontece apenas nos cursos de formação inicial, mas ao longo de toda a carreira docente. Direito, porque não pode ser negada aos professores, estando, inclusive, garantida na Lei de Diretrizes e Bases da Educação Nacional n 9.394/1996. Nesse cenário, especialmente a partir do início do século XXI, diversos programas governamentais de formação continuada de professores têm sido ofertados às redes públicas de ensino do país. No caso da formação de professores alfabetizadores, são exemplos o Programa de Formação de Professores Alfabetizadores (PROFA), o Pró-Letramento e, mais recentemente, o Pacto Nacional pela Alfabetização na Idade Certa (PNAIC).

O PNAIC, lançado pelo Governo Federal em 2012, constitui um compromisso formal dos governos federal, estaduais e municipais de assegurar que todas as crianças estejam alfabetizadas até os oito anos de idade, isto é, que concluam o 3ำ ano do ensino fundamental não apenas tendo compreendido o sistema de escrita alfabética e dominado as correspondências entre grafemas e fonemas, mas lendo e produzindo textos com autonomia. Uma das principais ações do Pacto é a formação continuada de professores alfabetizadores $^{3}$, a qual inclui curso presencial, com carga horária de 120 horas por ano, ministrado por orientadores de estudo, que são professores das redes de ensino, formados por universidades públicas em um curso específico de 220 horas por ano. Os princípios gerais da formação continuada assumidos pelo Programa são a prática da reflexividade, a mobilização dos saberes docentes, a constituição da identidade profissional, a socialização, o engajamento e a colaboração. (cf. BRASIL, 2012).

Nesse contexto, algumas questões impõem-se no que se refere às contribuições desse curso de formação continuada para as práticas de ensino de leitura e escrita dos professores alfabetizadores que dele participam: que orientações desse curso de formação continuada contribuíram para essas práticas? Como e por que essas

\footnotetext{
${ }^{3}$ Além da formação continuada, constituem eixos de atuação do Programa a distribuição de materiais didáticos, obras literárias e de apoio pedagógico, jogos e tecnologias educacionais, a realização de avaliações sistemáticas e a gestão, o controle e a mobilização social.
} 
orientações contribuíram? Que aspectos podem favorecer ou não a incorporação dessas orientações pelos professores ao seu repertório de práticas?

Gatti (2003) observa que, de modo geral, os mentores e implementadores de programas ou cursos de formação continuada consideram que as mudanças em posturas e formas de agir decorreriam do domínio de novos conhecimentos, os quais precisariam ser oferecidos aos professores. Segundo essa autora, essa concepção desconsidera que “(...) esses profissionais são pessoas integradas a grupos sociais de referência nos quais se gestam concepções de educação, de modos de ser, que se constituem em representações e valores que filtram os conhecimentos que lhes chegam" (p. 192). Falsarella (2003), por sua vez, alerta para a influência que o clima e a cultura escolares, a socialização docente na tradição da escola e o caráter dinâmico da sala de aula exercem sobre o trabalho do professor. Nessa perspectiva, essa autora ressalta que,

Quando colocados frente a uma proposta de mudança, os professores se indagam o que ela trará como resultado, não no abstrato, mas para cada um deles em seu próprio contexto, e fazem o que conseguem e acham que vale a pena dentro de suas circunstâncias concretas de trabalho e de vida. (FALSARELLA, p. 211).

Pode-se, assim, concluir que as mudanças nas práticas de ensino não ocorrem de maneira automática, como resultado direto e imediato dos cursos de formação dos quais os professorem participam. Em vez disso, compreendemos que os professores não recebem passivamente os conhecimentos e orientações a que têm acesso nos curso de formação inicial e continuada, porque são sujeitos inventivos e produtivos, que, por isso mesmo, apropriam-se das produções culturais, reinventando-as em seu cotidiano (cf. CERTEAU, 2012). Nesse processo, as “inovações" são avaliadas e validadas ou não pelos professores por meio de critérios pragmáticos e não teóricos, sendo incorporadas apenas quando contribuem, de alguma maneira, para uma melhor organização do trabalho pedagógico. Caso contrário, são adaptadas ou mesmo descartadas, principalmente quando parecem inúteis ou sem relação com a realidade vivida (CHARTIER, 2007; TARDIF, 2001).

Neste artigo, considerando as discussões tecidas anteriormente, apresentaremos alguns resultados de uma pesquisa que desenvolvemos com um grupo de professoras alfabetizadoras que tinham participado do curso de formação continuada do PNAIC no ano de 2013. 


\section{Contextualizando a pesquisa}

A pesquisa que desenvolvemos teve como objetivo investigar, a partir da perspectiva de professores alfabetizadores, as contribuições do curso de formação continuada do PNAIC para as suas práticas de ensino da leitura e da escrita no ciclo de alfabetização. Considerando a natureza desse objetivo, adotamos uma abordagem qualitativa de pesquisa, que se ocupa do universo de significados, motivos, aspirações, crenças, valores e atitudes (MINAYO, 2011). No entanto, como entendemos que não existe dicotomia entre qualidade e quantidade, recorremos também, quando necessário, a dados quantitativos.

Para atender aos objetivos de pesquisa explicitados anteriormente, utilizamos a entrevista semiestruturada como procedimento metodológico, a qual foi realizada com 10 professoras do ensino fundamental de escolas da rede pública municipal da cidade de Brejo da Madre de Deus - PE, sendo 7 delas docentes do $1^{10}$ ano e 3 de salas multisseriadas de escolas do campo, as quais se dispuseram a participar do estudo e atendiam aos seguintes critérios: 1) estar atuando no ciclo de alfabetização; 2) ter participado, no ano anterior, do curso de formação de alfabetizadores do PNAIC correspondente ao $1^{\circ}$ ano e/ou a turmas de escolas do campo que incluíssem o $1^{\circ}$ ano. A fim de resguardar a identidade das docentes, elas foram denominadas com os numerais de 1 a 10 , sendo as de 1 a 7 as que lecionavam no primeiro ano do ensino fundamental na época da formação e as de 8 a 10 as que atuavam em escolas do campo. No quadro apresentado a seguir, as professoras alfabetizadoras são caracterizadas no que se refere à formação e experiência profissional.

Quadro 1 - Formação e Perfil Profissional

\begin{tabular}{|c|c|c|c|}
\hline Professoras & $\begin{array}{l}\text { Ensino Médio (curso e } \\
\text { ano de conclusão) }\end{array}$ & Graduação (curso e ano de conclusão) & $\begin{array}{c}\text { Tempo de } \\
\text { atuação como } \\
\text { alfabetizadora }\end{array}$ \\
\hline \multirow{2}{*}{1} & Magistério/1994 & \multirow{2}{*}{ Geografia/2003 } & \multirow{2}{*}{32 anos } \\
\hline & Contabilidade/1997 & & \\
\hline 2 & Magistério/1994 & Pedagogia/1999 & 6 anos \\
\hline 3 & Magistério/1995 & Cursando Pedagogia & 16 anos \\
\hline 4 & Magistério/1993 & Pedagogia/2011 & 9 anos \\
\hline 5 & Magistério/1995 & História/2008 & 5 anos \\
\hline 6 & Magistério/1994 & Pedagogia/2004 & 14 anos \\
\hline 7 & Magistério/1998 & Ciências com Habilitação em Biologia/2002 & 17 anos \\
\hline 8 & Magistério/1996 & Pedagogia/2004 & 16 anos \\
\hline 9 & Normal médio/2010 & Cursando Pedagogia & 4 anos \\
\hline 10 & Normal médio/2010 & Cursando Física & 2 anos \\
\hline
\end{tabular}


Fonte: Acervo da pesquisa

A partir das informações expostas no Quadro 1, percebe-se, quanto à formação de nível médio, que todas as professoras cursaram o magistério. Em nível superior, a maioria possui graduação ou estava cursando Pedagogia. Entre as demais, uma é graduada em Geografia, uma em História, uma em Biologia e outra estava cursando licenciatura em Física. Com relação ao tempo de experiência como professoras do ciclo de alfabetização, a maioria atuava em uma faixa que variava de 9 a 32 anos e as mais novas na profissão ensinavam a 2, 4 e 6 anos.

Utilizamos como procedimento metodológico a entrevista semiestruturada, que consiste em uma série de perguntas verbais abertas, em uma ordem prevista, na qual o entrevistador pode acrescentar perguntas de esclarecimento (LAVILLE, DIONE, 1999). As entrevistas foram realizadas com gravação em áudio, utilizando um roteiro previamente elaborado, e foram usadas para gerar dados sobre as contribuições do curso de formação continuada do PNAIC para as suas práticas de ensino da leitura e da escrita, considerando os seguintes aspectos: a) as orientações do curso da formação continuada que contribuíram para essas práticas de ensino; b) como e porque essas orientações contribuíram para essas práticas; c) os aspectos favorecedores ou não da incorporação dessas orientações pelos professores. Também usamos a entrevista para mapear as experiências de formação e de atuação em sala de aula vivenciadas pelos professores.

Para realização da pesquisa, foi solicitada autorização para produção e análise dos dados, mediante utilização de Termo de Consentimento Livre e Esclarecido, assinado pelos professores entrevistados, assegurando o anonimato quando da divulgação dos resultados do estudo.

Os dados "brutos" obtidos foram submetidos a análises de conteúdo (BARDIN, 1979), a qual foi desenvolvida por temas (análise temática categorial) e envolveu as seguintes etapas: pré-análise, análise do material (codificação e categorização da informação) e tratamento dos resultados, inferência e interpretação.

\section{Formação continuada de professores: contribuições para o ensino da leitura e da escrita na alfabetização}

A partir da análise das entrevistas realizadas com as professoras alfabetizadoras participantes da pesquisa, construímos as seguintes categorias de análise, as quais serão tomadas como objeto de discussão a seguir: contribuições do curso de formação 
continuada do PNAIC para as práticas de ensino de leitura e escrita; cadernos do curso que mais contribuíram para as práticas de ensino da leitura e escrita; consulta aos cadernos do curso de formação; mudanças nas práticas de ensino de leitura e escrita influenciadas pelo curso de formação; dificuldades encontradas para realização das propostas do curso.

1.1 Contribuições do curso de formação continuada para as práticas de ensino de leitura e escrita

Foi unânime entre as professoras alfabetizadoras entrevistadas a afirmativa de que houve, de fato, contribuições do curso de formação continuada para suas práticas de ensino da leitura e da escrita. Esse dado aproxima-se dos resultados encontrados por Cardoso e Cardoso (2016), em uma pesquisa realizada com professores alfabetizadores ao término do $1^{\circ}$ ano de adoção do PNAIC no estado do Mato Grosso.

Nesse estudo, cujos dados foram gerados por meio da aplicação de um questionário e obteve 2.663 respostas, constatou-se que a maioria dos professores respondeu sim à pergunta "Este curso causou algum impacto na sua prática? Qual?" e mencionaram, de modo geral, os seguintes aspectos:

a organização do trabalho pedagógico; a forma de conduzir a aula, desde o planejamento até a rotina diária; novas formas de trabalhar com gênero; aprimoramento do trabalho em sala e novas formas de trabalhar a alfabetização; mais segurança para trabalhar com alunos com dificuldades; as diversas formas de trabalhar e abordar a leitura e a escrita. (CARDOSO; CARDOSO, 2016, p. 100).

Klein et al. (2016), por meio da análise das percepções de 1.515 professores alfabetizadores do noroeste paulista que participaram do PNAIC no ano de 2013, as quais foram geradas a partir um questionário online com questões abertas e fechadas, também constataram que a maior parte dos professores participantes da pesquisa (70\%) considerava que houve muito impacto da formação em suas práticas.

Os demais professores consideraram que esse impacto foi razoável (23\%) ou pouco (6\%). quadro a seguir, é possível visualizar as principais contribuições do curso de formação do PNAIC, segundo as professoras participantes de nossa pesquisa, para as suas práticas de ensino da leitura e da escrita.

\section{Quadro 2 - Contribuições do curso de formação do PNAIC para as práticas de ensino de leitura e escrita}




\begin{tabular}{|c|c|c|c|c|c|c|c|c|c|c|c|}
\cline { 2 - 9 } \multicolumn{2}{c|}{} & \multicolumn{7}{c|}{ Professoras } & \multicolumn{1}{c|}{} \\
\hline Contribuições & 1 & 2 & 3 & 4 & 5 & 6 & 7 & 8 & 9 & 10 & Total \\
\hline Ludicidade / jogos de alfabetização & & & & & & & & & & & 5 \\
\hline $\begin{array}{c}\text { Avanço dos alunos em leitura e } \\
\text { escrita }\end{array}$ & & & & & & & & & & & 4 \\
\hline Material do curso & & & & & & & & & & & 4 \\
\hline Inovação da dinâmica das aulas & & & & & & & & & & & 3 \\
\hline $\begin{array}{c}\text { Trabalho com le experiências } \\
\text { turmas multisseriadas escrita em }\end{array}$ & & & & & & & & & & & 2 \\
\hline
\end{tabular}

Fonte: Acervo da pesquisa.

Conforme podemos observar no Quadro 2, o aspecto mais citado pelas professoras e também mencionado pelos participantes do estudo de Cardoso e Cardoso (2016), foi "Ludicidade/jogos de alfabetização". Esse aspecto constitui, de fato, uma dimensão importante no ciclo de alfabetização, uma vez que as crianças, quando ingressam no Ensino Fundamental, não deixam de ser crianças e continuam tendo a necessidade e o direito de brincar. A seguir, alguns extratos de respostas dadas pelas professoras no que se refere a esse aspecto:

Eu aprendi a trabalhar com jogos, que eu tinha muita dificuldade, e, com isso, meus alunos do primeiro ano tiveram um melhor resultado na leitura e na escrita. (Professora 7).

Contribuiu, sim. Eu acho que principalmente a questão de como se trabalhar a leitura e a escrita de forma mais lúdica, com jogos. (Professora 9).

[...] lembro que era a parte dos jogos, que ensinava a gente a lidar com jogos, que, era quando o aluno começava a observar a escrita e a leitura como uma coisa do cotidiano deles. Por que aqueles joguinhos iam ensinar eles a escrever e a ler coisas do cotidiano dele, palavras que eram simples. (Professora 10).

As professoras também citaram o avanço das crianças na leitura e na escrita $(4 / 10)$ e os materiais do curso (4/10) como contribuições significativas do curso de formação. Quanto ao primeiro aspecto, mencionaram, de modo geral, melhoria na aprendizagem da leitura e a escrita e uma das docentes referiu-se especificamente ao desenvolvimento do gosto pela leitura pelos alunos. Já com relação aos materiais do curso, consideraram como muito bons. Três professoras também mencionaram a inovação da dinâmica das aulas e duas referiram-se à troca de experiência com os pares. Uma das alfabetizadoras que atuava em turmas multisseriadas mencionou como contribuição o trabalho com leitura e escrita nessas turmas. 
Apesar de reconhecerem as contribuições da formação para suas práticas de ensino da leitura e da escrita, duas professoras chamaram atenção para a atuação do orientador de estudo do curso, que, pela forma como conduzia os encontros, não as deixavam totalmente satisfeitas.

1.2 Cadernos do curso de formação que mais contribuíram para as práticas de ensino da leitura e escrita

Indagamos as professoras sobre quais cadernos do curso de formação consideravam que haviam contribuído mais para suas práticas de ensino da leitura e da escrita e obtivemos os resultados apresentados no Quadro 3. Conforme podemos observar, o caderno cujo tema é a ludicidade foi indicado pela maioria das professoras (8/10), o que se relaciona com os dados que obtivemos no que concerne às contribuições do curso de formação.

Quadro 3 - Cadernos do curso de formação que mais contribuíram para as práticas dos professores

\begin{tabular}{|c|c|c|c|c|c|c|c|c|c|c|c|}
\hline 年 & \multicolumn{10}{|c|}{ Professoras } & \multirow[b]{2}{*}{ Total } \\
\hline Cadernos & 1 & 2 & 3 & 4 & 5 & 6 & 7 & 8 & 9 & 10 & \\
\hline Currículo na alfabetização: concepções e princípios. & & & & & & & & & & & 0 \\
\hline $\begin{array}{c}\text { Planejamento escolar: alfabetização e ensino da língua } \\
\text { portuguesa. }\end{array}$ & & & & & & & & & & & 2 \\
\hline A aprendizagem do sistema de escrita alfabética. & & & & & & & & & & & 1 \\
\hline Ludicidade na sala de aula. & & & & & & & & & & & 8 \\
\hline Os diferentes textos em salas de alfabetização. & & & & & & & & & & & 3 \\
\hline $\begin{array}{l}\text { Planejando a alfabetização; integrando diferentes áreas do } \\
\text { conhecimento - projetos didáticos e sequências didáticas. }\end{array}$ & & & & & & & & & & & 2 \\
\hline $\begin{array}{c}\text { Alfabetização para todos: diferentes percursos, direitos } \\
\text { iguais. }\end{array}$ & & & & & & & & & & & 1 \\
\hline
\end{tabular}

Fonte: Acervo da pesquisa

Os extratos a seguir ilustram as falas de algumas das professoras que apontaram o caderno sobre a ludicidade como o mais significativo para as suas práticas de ensino da leitura e da escrita:

Foi ludicidade na sala de aula. [...] Vinha aqueles textos, aqueles tipos de poesias, aqueles poemas. Então chamou muito a atenção deles e foi muito proveitoso. Eu acho que a ludicidade ajuda [...] por que chama atenção, por que atrai. (Professora 1)

Contribuiu de forma qualitativa para a minha prática de ensino, uma vez que eu não tinha o hábito de alfabetizar com jogos e brincadeiras e esse caderno veio me auxiliar nessa questão. Todas as atividades dele são de fundamental importância para ajudar a criança ampliar sua linguagem, seus conhecimentos. [...] (Professora 6). 
Porque, começando aqui por essa parte do lúdico, é quando você desperta um olhar diferente no aluno em relação à aprendizagem, ele não vai mais ver aquilo como alguma coisa tão compromissada, tão séria, assim tão fechada. Mas ele pode lidar com aquilo de uma forma divertida, prazerosa de fazer. (Professora 10)

Esses depoimentos parecem revelar, assim, que as professoras reconhecem a importância do lúdico no processo de alfabetização, contemplando um dos objetivos do caderno em tela: "conhecer a importância do uso de jogos e brincadeiras no processo de apropriação do Sistema de Escrita Alfabética (SEA), analisando jogos e planejando aulas em que os jogos sejam incluídos como recursos didáticos" (BRASIL, 2012b, p. 5).

O caderno cujo tema refere-se à incorporação dos diversos gêneros textuais de circulação social no processo de alfabetização aparece como o segundo mais citado pelas professoras. As três entrevistadas que apontaram diretamente esse caderno foram as que lecionavam em escolas do campo. Uma das professoras afirmou:

[...] Essa questão de trabalhar os gêneros textuais eu achei interessante de fazer, que é porque, quando você começa a mostrar pra o aluno a importância da escrita e da leitura, onde se serve aquilo, onde é aplicado, aí ele começa a ver a utilidade de aprender a escrever, de aprender a ler. Porque ele vê aquilo como algo que vai servir pra ele na prática. (Professora 10).

Quanto a esse aspecto, notamos a valorização, pelas professoras, do trabalho com os gêneros textuais no ensino da leitura e da escrita, proporcionando aos alunos o contato com a diversidade textual durante o processo de alfabetização. Nesse sentido, Mendonça (2005, p. 48) observa que

não é preciso esperar que a criança esteja alfabetizada para deixá-la entrar em contato com textos dos mais diversos gêneros. Este é, a propósito, o princípio básico da proposta de alfabetizar letrando: a apropriação do sistema de escrita e a inserção nas práticas de leitura e escrita se dariam de forma simultânea e complementar.

Em estudo que se dedicou à analise das práticas de ensino da leitura e escrita de duas professoras alfabetizadoras em processo de formação continuada no âmbito do PNAIC, Silva, Melo e Mendes (2016) observaram, especialmente nas práticas de uma das professoras observadas, a exploração de gêneros textuais diversos na alfabetização. Essa mesma professora apontou, inclusive, o caderno do curso que aborda esse tema como o que mais estava contribuindo para suas práticas de ensino. Ela ainda indicou a ludicidade como uma temática tratada na formação que também considerava importante para as suas práticas. No caso da outra alfabetizadora, também foi possível observar 
certo impacto do curso no que se refere a esses aspectos, principalmente quanto ao uso das obras complementares e dos jogos de alfabetização.

\subsection{Consulta aos cadernos do curso de formação: frequência e motivos}

No que se refere à consulta aos cadernos do curso de formação continuada do PNAIC realizado em 2013, percebemos que quatro das dez professoras entrevistadas afirmaram consultar frequentemente esses materiais, três disseram que consultavam com menos frequência e outras três declararam que não recorriam aos cadernos, conforme podemos observar no quadro a seguir.

Quadro 4 - Frequência de consulta aos cadernos do curso de formação

\begin{tabular}{|c|c|c|c|c|c|c|c|c|c|c|c|}
\hline & \multicolumn{10}{|c|}{ Professoras } & \\
\hline Frequência & 1 & 2 & 3 & 4 & 5 & 6 & 7 & 8 & 9 & 10 & Total \\
\hline Frequentemente & & & & & & & & & & & 4 \\
\hline Às vezes & & & & & & & & & & & 3 \\
\hline Nunca & & & & & & & & & & & 3 \\
\hline
\end{tabular}

Fonte: Acervo da pesquisa

Entre as docentes que afirmaram nunca consultar os cadernos, a professora 4 alegou não fazê-lo por falta de tempo. Já as professoras 1 e 10 afirmaram ter realizado a consulta deles apenas durante a época do curso de formação: a primeira acrescentou que estava dedicando-se, naquele momento, à consulta dos cadernos da formação em Alfabetização Matemática ${ }^{4}$ e a segunda que consultava a anotações que realizou durante os encontros. Uma delas afirmou o seguinte:

Esse ano a gente deixa mais, porque a gente ta só na parte de matemática. Aí esse ano eu ainda não peguei neles não [...] Eu só utilizava enquanto estava na formação. [...] (Professora1).

No caso das alfabetizadoras que declararam consultar os cadernos às vezes, a professora 3, que também disse estar dedicando-se mais à consulta dos cadernos referentes à Alfabetização Matemática, declarou que consultava os cadernos do ano anterior quando conseguia articular as propostas do PNAIC às exigências do Alfabetizar com Sucesso, um outro programa em desenvolvimento no município. A professora 5 expôs que a falta de tempo fazia com que preferisse recorrer à internet, mas, quando surgia uma oportunidade e uma necessidade, recorria aos cadernos. Já a professora 7 indicou que consultava mais as anotações das orientações do curso. Além disso, essa

\footnotetext{
${ }^{4}$ A pesquisa foi realizada no segundo ano de implementação do PNAIC, quando os professores estavam realizando o curso de formação relativo à Alfabetização Matemática.
} 
última declarou não ter recebido o material durante a formação, aspecto também apontado por outra professora em outro momento da entrevista.

Entre os motivos apontados pelas docentes como motivadores dessa consulta, o planejamento de aulas apareceu nas falas da maioria delas (6/10); o esclarecimento de dúvidas com relação a conteúdos e metodologias também foi citado (5/10); a consulta para a elaboração de recursos didáticos e das seções que contém as indicações de livros foram elencadas por uma professora, cada aspecto. Houve ainda três professoras que alegaram ter realizado uma consulta mais sistemática durante o curso de formação, entre outras coisas por ser uma exigência do curso que o professor desenvolvesse em sua sala de aula algumas propostas e socializasse os resultados nos encontros de formação.

Indagada sobre a frequência e motivações para a consulta dos cadernos do curso de formação, uma das professoras expressou:

Sim, eu consulto sempre. Por ensinar agora aqui o primeiro ano na alfabetização, eu consulto sempre as partes que contemplam as leituras, que tem muitas indicações de livros. [...] As sequências didáticas, quando a gente tem alguma dúvida ou esquece alguma coisa, aí eu vou e sempre consulto. Sempre, toda semana, sempre vejo alguma coisa, quando tem algum projeto na escola. Os livros são muito bons, tem muitos projetos, muitas coisas com sequência. Eu sempre utilizo eles (sic) pra tirar uma dúvida, pra preparar aula. Então eu sempre consulto. (Professora 8).

Como pudemos observar, os materiais do curso de formação continuada ainda eram consultados pela maior parte dos docentes, mesmo após o término do referido curso. Os motivos apontados para essa consulta eram, principalmente, de natureza pragmática (planejamento de aulas, elaboração de recursos didáticos, retomada de indicações de livros para leitura em sala de aula, entre outros), coadunando-se com o que expõe Chartier (2007, p. 185): "Ao se defrontarem com texto acadêmicos, os professores privilegiam as informações diretamente utilizáveis, o "como fazer" mais do que o "porquê", os protocolos de ação mais do que as explicações ou os modelos".

De modo geral, no que concerne aos cadernos do curso de formação, eles foram avaliados muito positivamente pelas docentes e, segundo os depoimentos, serviam como suporte para consultas cotidianas, como apoio para a realização de projetos e sequências didáticas ou mesmo para tirar dúvidas durante a realização do planejamento. Dessa forma, podemos concluir que os materiais parecem proporcionar condições para mudanças na prática pedagógica e propiciavam um trabalho englobando as diferentes 
áreas de conhecimento. As sugestões de atividades e os relatos de experiências foram indicados como algo que dava segurança às professoras. No que se refere à linguagem do material, ela foi apontada como acessível e de fácil compreensão. As docentes também mencionaram, de modo geral, a proximidade desses materiais à realidade delas.

1.4 Mudanças nas práticas de ensino da leitura e da escrita proporcionadas pela formação

Falsarella (2003), ao discutir sobre o impacto da formação continuada na prática cotidiana dos professores, ressalta o caráter dinâmico das salas de aula, assim como as especificidades de cada uma delas e do contexto no qual cada professor está inserido. Assim, segundo a autora, ao se depararem com determinada proposta de mudança, o professor analisa as possibilidades dela surtir resultados práticos, tendo em vista a sua realidade. Nesse sentido, "é o professor que transforma a ideia de inovação em ato pedagógico inovador, é ele que abraça uma ideia, testa essa ideia na prática e apropriase dela ou não" (FALSARELLA, 2003, p. 214).

No estudo desenvolvido por Klein et al. (2016), a maior parte dos professores participantes declarou que as principais mudanças em suas práticas após a formação relacionavam-se à organização do trabalho pedagógico (como registro, planejamento, definição clara de objetivos, projetos, sequência didática, rotina e avaliação) e a mudanças metodológicas (como trabalho em grupo, participação ativa dos alunos, consideração da diversidade dos alunos, ênfase na aprendizagem, adequação das atividades ao nível dos alunos, trabalho com a heterogeneidade e mapeamento da turma, interdisciplinaridade). Já na pesquisa de Cardoso e Cardoso (2016), foram feitas referências, principalmente, às seguintes mudanças:

maior envolvimento dos alunos no processo ensino-aprendizagem; a forma de planejar, em especial, a sequência didática; a utilização da literatura diária nas leituras deleite; uso de projeto; o trabalho com o lúdico e o uso dos livros para planejamento de aula; a organização do cantinho da leitura para os alunos; o registro das atividades aplicadas em sala de aula. (p. 103).

As principais mudanças elencadas pelas professoras de nossa pesquisa relacionam-se intimamente às indicações dos cadernos considerados como os que mais contribuíram para as suas práticas de ensino da leitura e da escrita. Assim, o trabalho com textos/gêneros textuais e a inserção da ludicidade apareceram como as mudanças 
mais citadas. Entretanto, outras indicações, como a interdisciplinaridade, foram feitas pelas professoras, conforme podemos observar no quadro a seguir.

Quadro 5 - Principais mudanças nas práticas de ensino da leitura e da escrita

\begin{tabular}{|c|c|c|c|c|c|c|c|c|c|c|c|}
\hline & \multicolumn{10}{|c|}{ Professoras } & \\
\hline Mudanças apontadas & 1 & 2 & 3 & 4 & 5 & 6 & 7 & 8 & $\overline{9}$ & 10 & Total \\
\hline Trabalho com textos/gêneros textuais & & & & & & & & & & & 4 \\
\hline Ludicidade & & & & & & & & & & & 3 \\
\hline Interdisciplinaridade & & & & & & & & & & & 2 \\
\hline Trabalho em grupo & & & & & & & & & & & 1 \\
\hline Atividades & & & & & & & & & & & 2 \\
\hline
\end{tabular}

Fonte: Acervo da pesquisa

Desse modo, parece ter havido, por parte das professoras, a incorporação de propostas do curso de formação continuada em suas práticas de ensino de leitura e escrita. Todas afirmaram que houve alguma mudança e explicitaram que mudanças eram essas, com exceção da professora 4, que, apesar de dizer que houve mudanças em suas práticas, restringiu-se a dizer que havia alterado hábitos de ensino cristalizados.

É importante que considerarmos a condição de recriação dessas propostas, pois partimos da ideia de que, mesmo havendo a incorporação de sugestões da formação nas práticas de ensino, as professoras que dela participaram realizam uma releitura dessas propostas, pois o professor não é um mero reprodutor ou executor, e sim um sujeito crítico e transformador. O extrato de fala que apresentamos a seguir sobre as mudanças nas metodologias de alfabetização reforça o que aqui está sendo dito

[...] Eu lembro que eu tinha uma certa dificuldade [...] de alfabetizar usando textos [...] Por que antes do curso eu alfabetizava muito assim com palavras-chave, entendeu? Com a palavra tirando a sílaba. Eu tinha muita dificuldade, muita resistência em trabalhar com textos, entendeu? Aí depois eu fui mudando, mudei a minha prática e assim ficou mais claro pra mim (Professora 5).

[...] antigamente era muito comum as pessoas alfabetizar com as palavras ou com a sílaba, né? É um método comum e muito mais difícil, é uma palavra isolada, uma sílaba isolada. Hoje em dia existem professores que ainda alfabetizam desse jeito. Eu não quero dizer que é o certo, por que não existe método certo, né? Não é que você vai usar um texto e não vai voltar ao silábico. Mas é importante você trabalhar com texto, fica muito mais significativo pra o aluno, não é? (Professora 5).

O depoimento dessa professora desvenda que houve mudanças na maneira como alfabetizava, mas sem abrir mão de metodologias antes praticadas. Essa atitude pode 
apontar, segundo Duran (2007, p. 125-126), a possibilidade de entender "os modos como os professores incorporaram, transformaram ou resistiram às orientações impostas por uma ordem social dominante".

Ainda a esse respeito, essa mesma autora trata das invenções que os professores realizam para organizarem o cotidiano: "Tais invenções do/no cotidiano vão produzindo uma "cultura", saberes pedagógicos da escola, saberes produzidos por professores e alunos, na dialeticidade da vida cotidiana, na concretude do cotidiano escolar". (p. 127).

1.5 Dificuldades encontradas para realização das propostas do curso

Perguntamos às professoras se elas haviam enfrentado dificuldades para materializar as propostas do PNAIC. As dificuldades apresentadas pelas professoras, em ordem de recorrência, foram: pouca idade dos alunos; associação entre o PNAIC e o Alfabetizar com Sucesso; alfabetização com textos; articulação entre diferentes áreas do conhecimento; salas multisseriadas; comportamento dos alunos; acompanhamento pelo corpo pedagógico da escola; limitação do espaço físico da escola; trabalho com jogos educativos; e falta de recursos tecnológicos na escola (ver Quadro 6).

Quadro 6 Principais dificuldades encontradas pelas professoras para materializar as propostas do PNAIC

\begin{tabular}{|c|c|c|c|c|c|c|c|c|c|c|c|}
\hline & \multicolumn{10}{|c|}{ Professoras } & \\
\hline Dificuldades & 1 & 2 & 3 & 4 & 5 & 6 & 7 & 8 & 9 & 10 & Total \\
\hline Idade dos alunos/nível dos alunos & & & & & & & & & & & 4 \\
\hline $\begin{array}{l}\text { Articulação entre o PNAIC e o Alfabetizar } \\
\text { com Sucesso }\end{array}$ & & & & & & & & & & & 3 \\
\hline Trabalho com textos & & & & & & & & & & & 2 \\
\hline $\begin{array}{l}\text { Articulação de diferentes áreas de } \\
\text { conhecimento }\end{array}$ & & & & & & & & & & & 2 \\
\hline Salas multisseriadas & & & & & & & & & & & 2 \\
\hline Comportamento/interesse dos alunos & & & & & & & & & & & 2 \\
\hline $\begin{array}{l}\text { Acompanhamento pelo corpo pedagógico da } \\
\text { escola }\end{array}$ & & & & & & & & & & & 2 \\
\hline Limitação do espaço físico da escola & & & & & & & & & & & 1 \\
\hline Trabalho com jogos educativos & & & & & & & & & & & 1 \\
\hline Falta de recursos tecnológicos & & & & & & & & & & & 1 \\
\hline
\end{tabular}

Fonte: Acervo da pesquisa

A dificuldade mais recorrente, de acordo com as professoras, referiu-se à idade/nível dos alunos, que, segundo elas, seriam muito novos e, por vezes, não acompanhavam o nível de algumas propostas. No extrato a seguir é possível observar o depoimento de uma das docentes sobre essa questão: 
Eu mesma encontrei dificuldades por conta das minhas crianças serem muito novas [...] o aprendizado das crianças quando vem de outra série para o primeiro ano ainda é um pouquinho lento, não tão assimilando por conta dessa idade. (Professora 3).

Essa dificuldade mencionada pelas professoras parece apontar para o fato de se esperar que os alunos cheguem ao primeiro ano do ensino fundamental dominando um conjunto de determinadas habilidades necessárias à realização das atividades. Por outro lado, deve-se levar em consideração que, no primeiro ano, as crianças estão, muitas vezes, familiarizando-se com um universo novo, que, por vezes, requer que passem a se comportar de maneira diferente da que estavam habituadas. As professoras, conforme evidenciam os dados, pareciam considerar algumas propostas discutidas na formação complexas para as crianças. No entanto, considerando que se trata de um momento de transição, cabe ao professor, enquanto mediador, fazer intervenções para garantir o desenvolvimento desses alunos, considerando seu tempo e especificidades.

Outra dificuldade apontada pelas alfabetizadoras referiu-se à existência paralela de outro Programa, o Alfabetizar com Sucesso. Com início no ano de 2002 na rede estadual de ensino do Estado de Pernambuco, foi criado com o intuito de solucionar os altos índices de reprovação do ensino fundamental. Seu objetivo "era investir na formação de professores alfabetizadores, oportunizando estudos sistemáticos relativos à teoria e à prática de alfabetizar". (MORAES, 2006, p. 78). Segundo essa autora, os professores também receberam materiais didáticos e uma característica desse Programa é o monitoramento das atividades desenvolvidas no que se referem à frequência, livros lidos e avanço dos alunos quanto à leitura e à escrita.

As professoras que apontaram como dificuldade a articulação entre o Alfabetizar com Sucesso e o PNAIC alegaram que ambos apresentavam propostas e metodologias diferentes. Dessa forma, evidencia-se que a disparidade de encaminhamentos dificultava o trabalho com as propostas do PNAIC, tendo em vista que havia um roteiro de atividades do Alfabetizar com Sucesso para que as professoras seguissem, o qual era fiscalizado pelos coordenadores do projeto, o que pode ser atestado pelo depoimento a seguir:

O que me incomodou um pouco foi [...] o Alfabetizar com Sucesso, que o tempo todo não casava um com o outro, um era o oposto do outro. [...] Então, muitas vezes, há atividades que a gente queria realizar e não batia. Mesmo quando tinha as tarefas de casa do PNAIC que o orientador passava pra gente realizar determinada atividade e levar pra expor, a gente tinha essa dificuldade, porque as 
coordenadoras da escola elas cobravam o Alfabetizar o tempo todo. (Professora 9).

As demais dificuldades apontadas, mesmo aparecendo com menor recorrência nas falas das professoras, não deixam de ser relevantes para entendermos as dificuldades ante as propostas da formação. Se, por um lado, algumas dessas dificuldades referiam-se a aspectos relacionados às propostas do curso de formação (articulação de diferentes áreas de conhecimento, trabalho com textos e com jogos didáticos), outras remetiam, por outro lado, a aspectos não diretamente relacionados ao processo formativo (trabalho em salas multisseriadas, comportamento/interesse dos alunos, ausência de acompanhamento pelo corpo pedagógico da escola, limitação de espaço físico da escola e falta de recursos tecnológicos).

\section{Considerações finais}

A formação continuada de professores constitui um importante espaço nos qual os professores podem vivenciar um processo contínuo de reflexão sobre as suas práticas pedagógicas e as de seus pares. Nesse estudo, percebemos algumas impressões sobre aspectos que parecem contribuir ou não para a incorporação das orientações do curso de formação pelas professoras em suas práticas de ensino da leitura e da escrita.

Entre os elementos possivelmente favoráveis, encontram-se a proximidade das propostas à realidade da sala de aula, o que faz com que as professoras não as vejam como algo distante do cotidiano escolar e que, portanto, teria chances de "funcionar" na prática.

Vivenciar as experiências em sala de aula e apresentar e discutir os resultados durante os encontros da formação também seria favorável, pois essa socialização entre os colegas de trabalho pode constituir um momento privilegiado de troca de experiências.

Já os aspectos que poderiam não contribuir para a incorporação pelas professoras das orientações do curso de formação em suas práticas de ensino da leitura e da escrita relacionavam-se, em seus depoimentos, por um lado, à existência paralela de outro Programa, o Alfabetizar com Sucesso, e, por outro, à atuação do tutor do curso.

Outro aspecto observado refere-se ao fato de muitas professoras precisarem mudar algumas práticas consolidadas em sua trajetória de atuação profissional. Por fim, um elemento apontado que chamou a atenção referiu-se à idade dos alunos, pois algumas professoras citaram esse aspecto como uma dificuldade para realizar algumas 
das propostas da formação, pois, para algumas delas, muitas crianças do primeiro ano do ensino fundamental não acompanhariam o que era proposto.

Acreditamos, assim como Falsarella (2003, p. 215), que "a realidade é o filtro pelo qual a mudança é assimilada". Em outras palavras, a incorporação pelo professor do que é vivenciado na formação em suas práticas de ensino dependerá de diversos fatores, entre eles a sua realidade cotidiana de trabalho. Nesse sentido, vemos a necessidade de reconhecer os dilemas com os quais os professores convivem diariamente nos cursos de formação continuada.

\section{Referências}

BARDIN, L. Análise de conteúdo. Lisboa: Edições 70, 1979.

BRASIL. Secretaria de Educação Básica. Diretoria de Apoio à Gestão Educacional. Pacto Nacional pela Alfabetização na Idade Certa/MEC: Caderno de Formação. Brasília: MEC/SEB, 2012a.

BRASIL. Secretaria de Educação Básica. Diretoria de Apoio à Gestão Educacional. Pacto Nacional pela Alfabetização na Idade Certa/MEC: Ludicidade na sala de aula. Brasília: MEC/SEB, 2012b.

CARDoso, C. J.; CARDoSO, A. L. J. Formação continuada no contexto do Pacto Nacional pela Alfabetização na Idade Certa: alinhamento entre práticas, princípios formativos e objetivos. Práxis Educativa, Ponta Grossa, v. 11, n. 1, p. 89-106, jan./abr. 2016

CERTEAU, Michel de. A invenção do cotidiano. 19. ed. Petrópolis: Vozes, 2012.

CHARTIER, A-M. Práticas de leitura e escrita: história e atualidade. Belo Horizonte: CEALE: Autentica, 2007.

DURAN, M. C. G. Maneiras de pensar o cotidiano com Michel de Certeau. In: Diálogo Educ., Curitiba, v.7, n.22,p. 115-128, set./dez.2007.

FALSARELLA, A. M. A formação continuada de professores e seu impacto na prática cotidiana. Revista Psicopedagogia, v. 20, n. 63, p. 210-217, 2003.

GATTI, B. Formação continuada de professores: a questão psicossocial. Cadernos de Pesquisa, n. 119, p. 191-204, 2003.

KLEIN, A. M. et al. Os significados da formação docente desenvolvida pelo Pacto Nacional pela Alfabetização na Idade Certa. Práxis Educativa, Ponta Grossa, v. 11, n. 1, p. 129-150, jan./abr. 2016.

MENDONÇA, M. Gêneros: por onde anda o letramento? In: SANTOS, C. F.; MENDONÇA, M. Alfabetização e letramento: conceitos e relações. Belo Horizonte: Autêntica, 2005.

MINAYO, M. C. S. O desafio da pesquisa social. In MINAYO, M. C. S. (Org.) Pesquisa social: teoria, método e criatividade. 30. ed. Petrópolis, RJ: Vozes, 2011. 
MORAES, D. A. As práticas de alfabetização de professores da rede estadual de ensino de Pernambuco e a formação de crianças alfabetizadas e letradas. Dissertação (Mestrado em Educação), 2006.

SILVA, A.; MENDES, E. P. S.; MELO, J. R.. Práticas de ensino de leitura e escrita de professoras alfabetizadoras em processo de formação. Interfaces Científicas Educação, v. 4, n. 2, p. 11-22, 2016.

TARDIF, M. Saberes docentes e formação profissional. Petrópolis: Vozes, 2002. 